\title{
Telemedicine in Patients with Chronic Diseases: The Time of Maturity!
}

\author{
E. Andrès ${ }^{a *, b}$, S. Talha ${ }^{b, c}$, M. Hajjam ${ }^{\text {d }}$ A. Hajjam ${ }^{\mathrm{e}}$ \\ aService de Médecine interne, Diabète et Maladies métaboliques de la cliniquemédicale B, \\ HôpitauxUniversitaires de Strasbourg, 1, porte de l'Hôpital, 67091 Strasbourg cedex, France

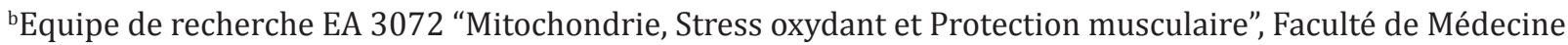 \\ de Strasbourg, Université de Strasbourg (UdS), 4 rue Kirschleger, France \\ 'Service de Physiologie et d'Explorationsfonctionnelles, HôpitauxUniversitaires de Strasbourg, 1, porte de \\ l'Hôpital, 67091 Strasbourg cedex, France \\ 'PREDIMED Technology, Mulhouse, France \\ 'Equipe de recherche EA 4662 "Nanomédecine, Imagerie, Thérapeutiques", Université de Technologie de \\ Belfort-Montbéliard (UTBM), Belfort-Montbéliard, France \\ *Corresponding Author: E. Andrès, Service de Médecine interne, Diabèteet Maladies métaboliques de la \\ cliniquemédicale B, HôpitauxUniversitaires de Strasbourg, 1, porte de l'Hôpital, 67091 Strasbourg cedex, France
}

\section{Abstract}

Here, we carry out a review of the literature focused on telemedicine projects developed in the field of heart failure. We will particularly detail the remote monitoring project called E-care, dedicated to automated, intelligent detection of situations at risk of heart failure. Prospects for the development of the E-care system in the field of Geriatry will also be discussed.

Keywords: Telemedicine. Heart failure. Geriatrics.

The rising prevalence of chronic diseases like chronic heart failure combined with population aging now represents a very real problem for public health [1]. The cost of these chronic diseases has rocketed, and is estimated at several billion dollars in developed countries. What's more, these patients are often elderly and have one or more chronic diseases, and their management is a challenge for healthcare professionals. Their needs eat up large amounts of medical resources, just as a shortage in the time careers can provide is beginning to be felt, with medical deserts and a lack of access to healthcare professionals, among other problems. Thus, our societies must "reinvent the medicine of today"!

Despite the advances in treatment of recent years, most chronic pathologies remain serious diseases in terms of their functional or survival prognosis, and morbidity and mortality are high [1]. This applies to heart failure, in which the mortality rate of patients with stage III-IV disease according to the New York Heart Association (NYHA) classification is at least 30\% at 5 years in more recent studies. Heart failure patients frequently present for emergency hospitalization and re-hospitalization, which impairs the quality of their life. Some of these hospitalizations could be avoided if patients took greater responsibility for their disease and were followed up better. This last point has been particularly well documented in heart failure and diabetes. Telemedicine may be of aid in this setting. Indeed it may even optimize the management of such chronic diseases, particularly by preventing emergency and repeat hospitalizations [2]. It may also make it possible to structure integrated care pathways.

Since the beginning of the 2000's, numerous telemedicine projects have been conceived and developed in the area of heart failure [3-21]. Practically all of them have investigated telemonitoring (or tele management, as it is also known) with a focus on heart failure patients. Some of the projects have very specifically investigated heart failure subjects aged over 75 or over $80[20,21]$. The results of those telemedicine projects differed from study to study and were fairly inconclusive regarding any potential clinical benefit in terms of, for instance, re-hospitalization or 
a decrease in morbidity and mortality. Nevertheless, several reviews and meta-analyses seem to have shown an undeniable utility for telemedicine. Moreover, aside from the medical considerations, it is worth noting that all the studies seem to agree that using telemedicine solutions in the management of heart failure was at least economically beneficial. Depending on the study, the savings were calculated to be between $\$ 5000$ and more than $\$ 50,000 /$ year/patient depending on the stage of heart failure and the setting of the study. It is worth bearing in mind that those projects, particularly the earlier ones, more closely resembled telephone follow-up with care providers (such as a nurse) traveling to the patient's home, rather than telemedicine as we think of it nowadays with nonintrusive, automated, smart telemonitoring using remote sensors via modern communication technology or even artificial intelligence [18]. Hence in our opinion those studies represent the first generation of telemedicine projects: "telemedicine 1.0" [18].

Over the last 4 to 5 years, a second generation of projects has emerged in the heart failure area, particularly in developed countries [18]. These projects are known as "telemedicine 2.0", because they utilize the new Information and Communication Technology (ICT) and the web. Most of these projects rely on the usual connected tools for monitoring heart failure, such as blood pressure meters, weighing scales, and pulse oximeters, which relay the information collected via Bluetooth, 3G or 4G and incorporate tools for interaction between the patient and healthcare professionals like telephone support centers, tablets, and websites [18]. Some of them also provide tools for motivation and education, and occasionally, questionnaires about symptoms, such as dyspnea, palpitation and edema as experienced by the patient.

The E-care telemonitoring project in Strasbourg falls under this category of "telemedicine 2.0" [22,23]. It has been developed to optimize the home-monitoring of heart failure patients. It detects situations in which there is a risk of cardiac decompensation and rehospitalization, and it does this via a telemonitoring 2.0 platform. The E-care platform generates indicators of a worsening of the patient's health status. These "warning alerts" are generated for any decompensation of a chronic disease (particularly heart failure) that may lead to hospitalization if not treated. Between February 2014 and April 2015, 175 patients were given the chance to use the E-care platform in the Strasbourg University Hospital [24]. During this period, the E-care platform was used on a daily basis by patients and healthcare professionals according to a defined protocol of use specific to each patient. The mean age of these patients was 72 years and the ratio of men to women was 0.7 . The patients suffered from multiple concomitant diseases and had a mean Charlson index of 4.1. During the study, 1500 measurements were taken in these 175 patients, which resulted in the E-care system generating 700 alerts in 68 patients. Analysis of the "warning alerts" showed that the E-care platform automatically and nonintrusively detected any worsening of the patient's health, particularly cardiac decompensation. Indeed, it was in this last setting that the system yielded the best sensitivity, specificity, and positive and negative predictive values, respectively 100\%, 72\%, 90\% and $100 \%$. Both the healthcare professionals and all the patients, even the frailest, used the E-care system without difficulty until the end of the study. During the study of non-autonomous patients, the system was employed by a nurse in addition to other tasks like washing and administering medication, as well as by close ones and family members. Hence, it has been our experience that age is not a limiting factor on grasping and using new technologies. Several recent studies have reached the same conclusion, documenting the use of telemedicine solutions even among 80-year-olds [25].

The platform is also capable of structuring the patients' care pathways, a major theme in medicine for our governments and authorities; it is also capable of providing a means for the various healthcare professionals to exchange with each other; and of facilitating access to medical resources. With this in mind, an enhanced version of the E-care platform will be experimented in the homes of heart failure patients as part of a project called PRADO INCADO. PRADO is a French program to support patients returning home after hospital, while PRADO INCADO will specifically target heart failure patients in this setting with the support of the E-care plateform (Fig. 1). The project is being run by a group bringing together Strasbourg University Hospital, the Alsatian Regional Health Agency, the Bas-Rhin branch of France's National Health Insurance, and the company PREDIMED Technology.

Besides heart failure, the opportunities in geriatrics revolve around developing new versions of E-care to enable "global" 2.0 telemonitoring of elderly subjects 
Telemedicine in Patients with Chronic Diseases: The Time of Maturity!

in nursing homes or at home, as opposed to singledisease telemonitoring as currently offered by a large number of telemedicine projects and solutions [18]. As with E-care, the "telemedicine 2.0 " projects are perfectly compatible with the care pathways being developed in chronic diseases by the developed countries health authorities. What's more, all these findings should be analyzed with regard to the benefit of these telemedicine solutions. This experience may lead us to witness the birth of the medicine of tomorrow. In the field of chronic diseases, given the epidemiology and expected shortage of time careers can provide, what we need is better followup and better education, improved prevention and anticipation, but, above all, better selection of the patients whose use of the healthcare system will be indispensable.

In conclusion, as far as we can tell, it is the first time that this kind of connected, smart system has been developed with the aid of tools from new technologies, prefiguring the solutions of telemedicine 2.0. In view of this experiment, it seems to us that telemedicine has reached its maturity

\section{CONFLICTS OF INTEREST}

The authors state that they have no conflicts of interest to declare except Mr M. Hajjam, who is the science director of the company PREDIMED Technology.

\section{FUNDING}

E-care was funded by the first call for tenders of the 2014 "Investment in the Future" initiative in France. PRADO INCADO is funded by the regional health agency of the north-east of France.

\section{ACKNOWLEDGMENTS}

Our thanks to Ms. C. Gentille, Mr. B. Boutteau, Ms. S. Mansion, and Ms. M.P. We wish to extend our gratitude to Ms. C. Geiller, Ms. A. Drexler and Mr. C. Gautier who believed in our project from the start, supported us and make it possible for us to go further.

\section{REFERENCES}

[1] http://invs.santepubliquefrance.fr/publications/ etat_sante_2017/ESP2017_Ouvrage_complet_vdef. pdf [janvier 2018].

[2] Anker SD, Koehler F, Abraham WT. Telemedicine and remote management of patients with heart failure. Lancet 2011; 378: 731-9.
[3] Rosen D, McCall JD, Primack BA. Telehealth Protocol to Prevent Readmission Among HighRisk Patients With Congestive Heart Failure. Am J Med 2017; 130: 1326-30.

[4] Burdese E, Testa M, Raucci P, Ferreri C, Giovannini $\mathrm{G}$, Lombardo E, et al. Usefulness of a Telemedicine Program in Refractory Older Congestive Heart Failure Patients. Diseases 2018; 6; doi:10.3390/ diseases6010010.

[5] Feltner C, Jones CD, Cené CW, Zheng ZJ, Sueta CA, Coker-Schwimmer EJ, et al. Transitional care interventions to prevent readmissions for persons with heart failure: a systematic review and meta-analysis. Ann Intern Med 2014; 160: 774-84.

[6] Martínez-González NA, Berchtold P, Ullman K, Busato A, Egger M. Integrated care programmes for adults with chronic conditions: a meta-review. Int J Qual Health Care 2014; 26: 561-70.

[7] Achelrod D. Policy expectations and reality of telemedicine - a critical analysis of health care outcomes, costs and acceptance for congestive heart failure. J TelemedTelecare 2014; 20: 192-200.

[8] Pandor A, Thokala P, Gomersall T, Baalbaki H, Stevens JW,Wang J, et al. Home telemonitoring or structured telephone support programmes after recent discharge in patients with heart failure: systematic review and economic evaluation. Health Technol Assess 2013; 17: 1-207.

[9] Kraai IH, Luttik ML, de Jong RM, Jaarsma T, Hillege HL. Heart failure patients monitored with telemedicine: patient satisfaction, a review of the literature. J Card Fail 2011; 17: 684-90.

[10] Dendale P, De Keulenaer G, Troisfontaines P, Weytjens C, Mullens W, Elegeert I, et al. Effect of a telemonitoring-facilitated collaboration between general practitioner and heart failure clinic on mortality and rehospitalization rates in severe heart failure: the TEMA-HF 1 (TElemonitoring in the MAnagement of Heart Failure) study. Eur J Heart Fail 2012; 14: 333-40.

[11] Di Lenarda A, Caloso G, Gulizia MM, Aspromonte $\mathrm{N}$, Scalvini S, Mortara A, et al. The future of telemedicine for the management of heart failure patients: a Consensus Document of the Italian Association of Hospital Cardiologists 
Telemedicine in Patients with Chronic Diseases: The Time of Maturity!

(A.N.M.C.O), the Italian Society of Cardiology (S.I.C.) and the Italian Society for Telemedicine and eHealth (Digital S.I.T.) Health Inform Res 2015; 21: 223-9.

[12] http://www.thecochranelibrary.com/userfiles/ ccoch/file/Telemedicine/CD007228.pdf [janvier 2018].

[13] Willemse E, Adriaenssens J, Dilles T, Remmen R. Do telemonitoring projects of heart failure fit the chronic care model? Int J Integr Care 2014; 14: e023.

[14] Inglis SC, Clark RA, McAlister FA, Ball J, Lewinter C, Cullington D, Stewart S, etal. Structured telephone support or telemonitoringprogrammes. Cochrane Database Syst Rev 2010; 8: CD007228.

[15] Chaudhry SI, Mattera JA, Curtis JP, Spertus JA, Herrin J, Lin Z, Phillips CO, et al. Telemonitoring in patients with heart failure. N Engl J Med 2010; 363: 2301-9.

[16] Koehler F, Winkler S, Schieber M, Sechtem $\mathrm{U}$, Stangl K, Böhm M, Boll H, et al. Impact of remote telemedical management on mortality and hospitalizations in ambulatory patients with chronic heart failure: the telemedical interventional monitoring in heart failure study. Circulation 2011; 123: 1873-80.

[17] Kitsiou S, Paré G, Jaana M. Systematic reviews and meta-analyses of home telemonitoring interventions for patients with chronic diseases: a critical assessment of their methodological quality. J Med Internet Res 2013; 15: e150.

[18] Andrès E, Talha S, Hajjam M, Hajjam J, Ervé S, Hajjam A. E-care project: a promising e-plateform for the optimizing management of chronic heart failure and other chronic diseases. Heart Res Open J 2015; 1: 39-45.
[19] Scalvini S, Capomolla S, Zanelli E, Benigno M, Domenighini D, Paletta L, et al. Effect of homebased telecardiology on chronic heart failure: costs and outcomes. J TelemedTelecare 2005; 11 Suppl 1: 16-8.

[20] Burdese E, Testa M, Raucci P, Ferreri C, Giovannini G, Lombardo E, Avogadri E, Feola M. Usefulness of a Telemedicine Program in Refractory Older Congestive Heart Failure Patients. Diseases 2018; 6, 10. Doi:10.3390/diseases6010010

[21] Kaladjurdjevic M, Antonicelli R. Evaluation of motivation and attitude for Telehomecare among caregivers of elderly patients affected with congestive heart failure. Digital Medicine 2016; 2 :149-56.

[22] Andrès E, Talha $S$, Ahmed Benyahia A, Keller 0 , Hajjam M, Moukadem A, et al. Expérimentation d'une plateforme de détection automatisée des situations à risque de décompensation cardiaque (plateforme E-care) dans une unité de Médecine Interne. Rev Med Interne 2016; 37: 587-93.

[23] Andrès E, Talha $S$, Benyahia AA, Keller 0 , Hajjam M, Moukadem A, et al. e-Health : a promising solution for the optimized management of chronic diseases. Example of a national e-Health project E-care based on a e-plateform in the context of chronic heart failure. EuropeanResearch in Telemedicine/La Recherche Européenne en Télémédecine 2015; 4: 87-94.

[24] Andrès E, Talha S, Hajjam M, Keller O, Hajjam J, Ervé S, HajjamA. Résultats de l'expérimentation d'une plateforme de détection automatisée des situations à risque de décompensation cardiaque (plateformeE-care) auprès de patientsprésentant des pathologies chroniques, suivis en médecine interne. Rev Med Interne 2018 : in press.

[25] Bashi N, Karunanithi M, Fatehi F, Ding H, Walters D. Remote Monitoring of Patients With Heart Failure: An Overview of Systematic Reviews. J Med Internet Res 2017; 19: e18.

Citation: E. Andrès, S. Talha, M. Hajjam, A. Hajjam. Telemedicine in Patients with Chronic Diseases: The Time of Maturity!. Open Access Journal of Internal Medicine. 2018; 1(1): 1-4.

Copyright: (C) 2018 E. Andrès, S. Talha, M. Hajjam, A. Hajjam. This is an open access article distributed under the Creative Commons Attribution License, which permits unrestricted use, distribution, and reproduction in any medium, provided the original work is properly cited. 